Subscriber access provided by University of East Anglia Library

\title{
Letter
}

\section{The Effect of Conjugation on the Competition Between Internal Conversion and Electron Detachment: A Comparison Between Green Fluorescent and Red Kaede Protein Chromophores}

Jamie Tay, Michael Anthony Parkes, Kiri Addison, Yohan Chan, Lijuan Zhang, Helen C. Hailes, Philip C. Bulman Page, Stephen R. Meech, Lluís Blancafort, and Helen H. Fielding

J. Phys. Chem. Lett., Just Accepted Manuscript • DOI: 10.1021/acs.jpclett.7b00174 • Publication Date (Web): 26 Jan 2017

Downloaded from http://pubs.acs.org on January 30, 2017

\section{Just Accepted}

"Just Accepted" manuscripts have been peer-reviewed and accepted for publication. They are posted online prior to technical editing, formatting for publication and author proofing. The American Chemical Society provides "Just Accepted" as a free service to the research community to expedite the dissemination of scientific material as soon as possible after acceptance. "Just Accepted" manuscripts appear in full in PDF format accompanied by an HTML abstract. "Just Accepted" manuscripts have been fully peer reviewed, but should not be considered the official version of record. They are accessible to all readers and citable by the Digital Object Identifier (DOI®). "Just Accepted" is an optional service offered to authors. Therefore, the "Just Accepted" Web site may not include all articles that will be published in the journal. After a manuscript is technically edited and formatted, it will be removed from the "Just Accepted" Web site and published as an ASAP article. Note that technical editing may introduce minor changes to the manuscript text and/or graphics which could affect content, and all legal disclaimers and ethical guidelines that apply to the journal pertain. ACS cannot be held responsible for errors or consequences arising from the use of information contained in these "Just Accepted" manuscripts. 


\title{
The Effect of Conjugation on the Competition
}

\author{
between Internal Conversion and Electron
}

Detachment: A Comparison between Green

Fluorescent and Red Kaede Protein Chromophores

Jamie Tay ${ }^{1}$, Michael A. Parkes, ${ }^{1}$ Kiri Addison, ${ }^{2}$ Yohan Chan, ${ }^{2}$ Lijuan Zhang, ${ }^{1}$ Helen C. Hailes, ${ }^{1}$

Philip C. Bulman Page, ${ }^{2}$ Stephen R. Meech, ${ }^{2}$ Lluís Blancafort,${ }^{* 3}$ Helen H. Fielding ${ }^{* 1}$

${ }^{1}$ Department of Chemistry, University College London, 20 Gordon Street, London WC1H 0AJ, UK. ${ }^{3}$ Institut de Química Computacional i Catàlisi and Departament de Química, Universitat de Girona, Facultat de Ciències, Campus de Montilivi, C/ M. A. Campmany 69, 17003 Girona.

\author{
AUTHOR INFORMATION \\ Corresponding Authors \\ *E-mail: 1luis.blancafort@udg.edu. \\ *E-mail: h.h.fielding@ucl.ac.uk
}


ABSTRACT. Kaede, an analogue of green fluorescent protein (GFP), is a green-to-red photoconvertible fluorescent protein used as an in vivo 'optical highlighter' in bioimaging. The fluorescence quantum yield of the red Kaede protein is lower than that of GFP, suggesting that increasing the conjugation modifies the electronic relaxation pathway. Using a combination of anion photoelectron spectroscopy and electronic structure calculations, we find that the isolated red Kaede protein chromophore in the gas phase is deprotonated at the imidazole ring, unlike the GFP chromophore that is deprotonated at the phenol ring. We find evidence of an efficient electronic relaxation pathway from higher lying electronically excited states to the $S_{1}$ state of the red Kaede chromophore that is not accessible in the GFP chromophore. Rapid autodetachment from high lying vibrational states of $S_{1}$ is found to compete efficiently with internal conversion to the ground electronic state.

\section{TOC GRAPHICS}

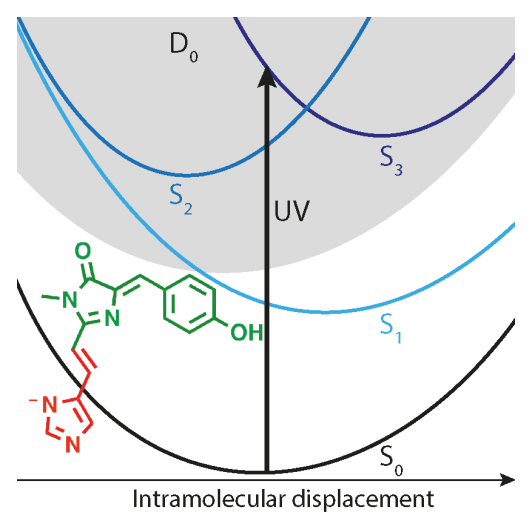

KEYWORDS. Spectroscopy, Computational Chemistry, Photochemistry, Non-radiative decay. 
Green fluorescent proteins (GFP) and its family of variants are used widely as non-invasive fluorescent probes for in vivo monitoring of biological and biochemical processes. ${ }^{1-6}$ The wildtype GFP chromophore, $p$-hydroxybenzylidene-2,3-dimethylimidazolinone ( $p$ HBDI, Fig. 1), is formed by the cyclisation and oxidation of $\mathrm{Ser}^{65}-\mathrm{Tyr}^{66}-\mathrm{Gly}^{67}$ amino acid residues and is embedded within a $\beta$-barrel protein structure..$^{1,47-10}$ The chromophore exists in deprotonated anionic $\left(p \mathrm{HBDI}^{-}\right)$or neutral forms and excitation of either of these leads to fluorescence from the deprotonated anionic chromophore at around $508 \mathrm{~nm}$, with a quantum yield of $\Phi=0.79^{11-14}$ (the neutral form deprotonates upon photoexcitation, yielding the anionic form). ${ }^{11,15}$ An interesting feature of the isolated GFP chromophore is that it is non-fluorescent, in both solution and gasphases, ${ }^{12,14,16-17}$ as a result of efficient ultrafast non-radiative decay pathways being accessible in the absence of the protein. ${ }^{18}$
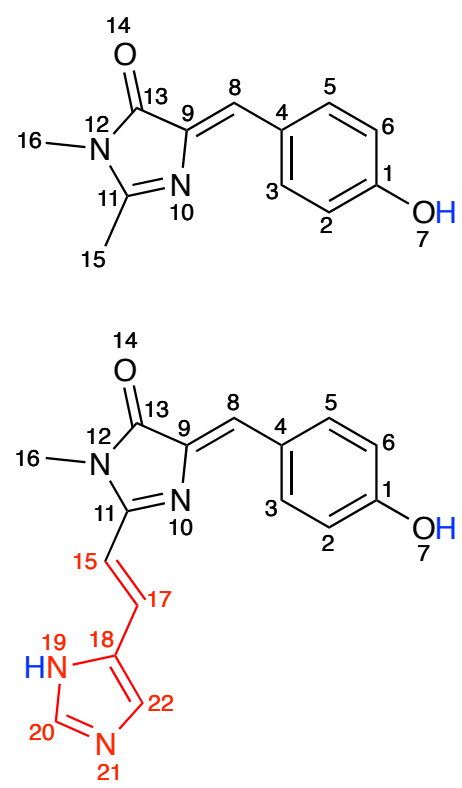

\footnotetext{
Fig. 1 Structure of the model GFP chromophore, p-hydroxybenzylidene-2,3 dimethylimidazolinone ( $p \mathrm{HBDI}$ ) (top) and the model rKaede chromophore (bottom). Possible deprotonation sites are highlighted in blue.
} 
For multi-labelling experiments, GFP variants with high visual contrast are desirable..$^{19-20}$ Kaede, an analogue of GFP, is a green-to-red photoconvertible fluorescent protein. ${ }^{19,21-22}$ It has a GFP-like chromophore, thus fluorescing green (green Kaede) following irradiation at $480 \mathrm{~nm} .^{19-22}$ Upon exposure to ultraviolet (UV) light $(350-420 \mathrm{~nm})$, green Kaede converts efficiently and irreversibly into a red fluorescent form (rKaede). ${ }^{19-21}$ This green-to-red fluorescence conversion produces an easily distinguishable bright and stable red colour that is not present in the unirradiated sample. ${ }^{1,19}$ Selective UV irradiation of cells expressing the Kaede protein enables it to be used as an in vivo 'optical highlighter' in bioimaging., ${ }^{1,21}$ Importantly, the excitation wavelengths needed to generate the red or green fluorescence do not induce photoconversion. ${ }^{19}$

The green-to-red photoconversion of Kaede has been the subject of several studies. ${ }^{21,23}$ Briefly, UV light causes a $\mathrm{C}_{\alpha}-\mathrm{N}_{\alpha}$ bond cleavage of the green Kaede chromophore, which is followed by deprotonation which in turn leads to the extended $\pi$-conjugated system that red-shifts the emission. $^{21,23}$ The green Kaede chromophore, made up of a tripeptide of $\mathrm{His}^{62}-\mathrm{Tyr}^{63}-\mathrm{Gly}^{64}{ }^{21,23}$ is similar to that of GFP; however, relatively little is known about the photophysics of the isolated model rKaede chromophore, 2-[(1E)-2-(5-imidazolyl)ethenyl]-4-(p-hydroxybenzylidene)-5imidazolinone (Fig. 1) ${ }^{21}$ Since the fluorescence quantum yield of the rKaede protein, $\Phi=0.33$, is lower than that of GFP, ${ }^{19}$ it seems likely that non-radiative decay pathways play a more important role in the excited state dynamics of the rKaede protein.

The aim of this combined photoelectron spectroscopy and computational study of the rKaede chromophore is to shed new light on how the extended conjugation affects non-radiative processes in the gas-phase. Understanding the intrinsic properties of the rKaede chromophore is important as it is a first step towards understanding such processes in the protein; for example, the higher lying electronic states of the GFP chromophore in the gas-phase undergo efficient 
electron detachment and in the protein are resonant with a quasi-continuum of solvated electron states, enhancing electron transfer from GFP to the solvent. ${ }^{24}$

Several recent experimental and theoretical investigations of $p \mathrm{HBDI}^{-}$in the gas-phase have identified two dominant competing radiationless relaxation channels - fragmentation, following IC back to the ground electronic state, and electron detachment. ${ }^{16,18,24-34}$ Experimental photoelectron spectroscopy studies and quantum chemistry calculations of gas-phase $p \mathrm{HBDI}^{-}$ have revealed that both direct and indirect electron detachment processes play an important role in the deactivation of isolated $p \mathrm{HBDI}^{-} \cdot{ }^{16,18,24,26-35}$ Close to the detachment threshold, around 355 $\mathrm{nm}$, direct photodetachment dominates. This wavelength corresponds to a minimum in the overall action absorption spectrum, lying above the maximum absorption cross-section to the first, bright electronically excited state, but below the onset of significant absorption crosssection to higher-lying electronically excited states. In fact, vibrationally-resolved photoelectron spectra of cold $\mathrm{pHBDI}^{-}$recorded at $355 \mathrm{~nm}$ have confirmed the adiabatic detachment threshold to be $2.73 \mathrm{eV}(454 \mathrm{~nm})^{27}$ in agreement with calculations. ${ }^{36}$ Above the photodetachment threshold, in the $350-315 \mathrm{~nm}$ photoexcitation range, indirect electron emission via resonant excitation of higher lying electronically excited states is also possible. Although there are many excited states and competing non-adiabatic decay pathways, the electron emission is dominated by a single, optically bright, excited state shape resonance that is strongly coupled to the electronic continuum. $^{24,37}$

The rKaede chromophore has two deprotonation states: the $\mathrm{O}(-)$ form which is deprotonated at the $\mathrm{O}_{7}$ position on the phenol group (as in $p-\mathrm{HBDI}^{-}$), or the $\mathrm{N}(-)$ form which is deprotonated at the $\mathrm{N}_{19}$ or $\mathrm{N}_{21}$ positions on the imidazole group. Studies of the wild-type rKaede protein have 

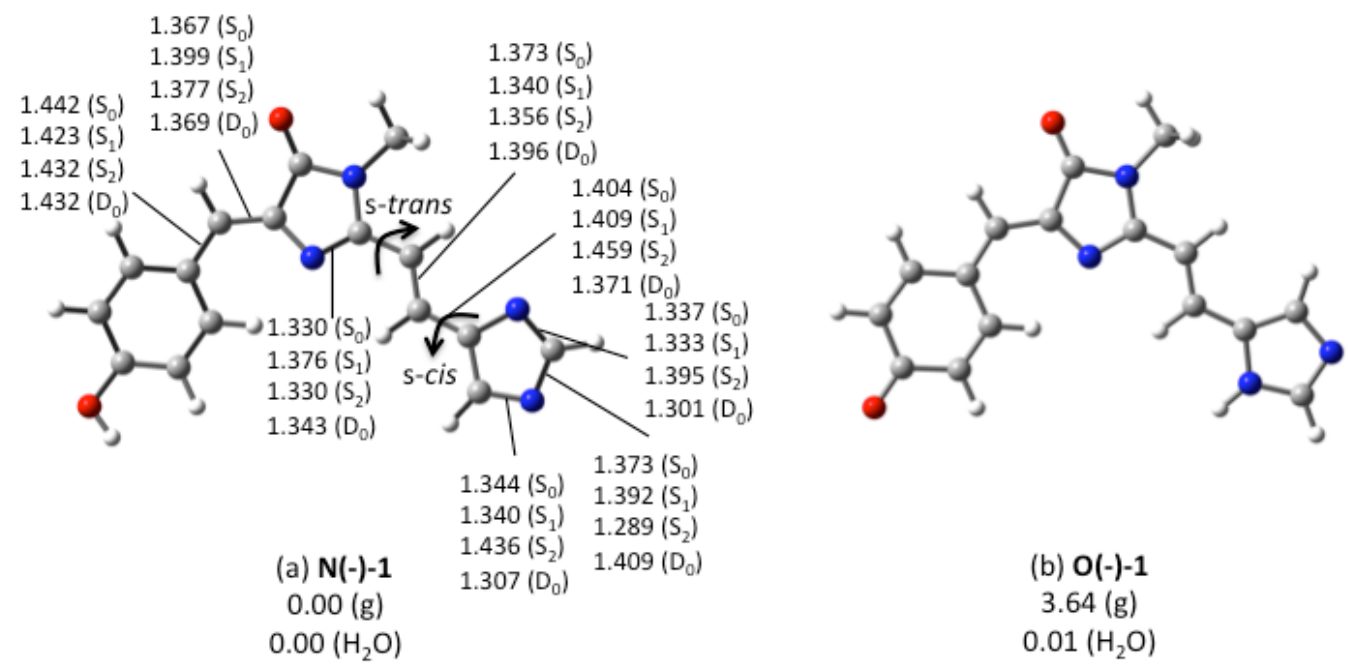

(b) $0(-)-1$

$3.64(\mathrm{~g})$

$0.01\left(\mathrm{H}_{2} \mathrm{O}\right)$

Fig. 2 Structures of (a) N(-)-1 and (b) O(-)-1 conformers of the rKaede chromophore anion. Representative bondlengths of the $\mathrm{N}(-)-1 \mathrm{~S}_{0}, \mathrm{~S}_{1}$ and $\mathrm{D}_{0}$ minima obtained with different methods (see text) given in $\AA$. Relative energies in the gas phase (g) and in water in $\mathrm{kcal} \mathrm{mol}^{-1}$ at the bottom of the figure.

revealed the chromophore in the protein to be deprotonated at the phenolic oxygen..$^{21,23}$ The $\mathrm{p} K_{\mathrm{a}}$ of unsubstituted imidazole in water $(14.52)^{38}$ is higher than that of phenol (9.95), suggesting that the phenoxy form might be the more stable form of the deprotonated isolated chromophore in the gas phase; however, MP2 calculations on seven $\mathrm{N}(-)$ and $\mathrm{O}(-)$ rKaede isomers with different side chain conformations indicate that the $\mathrm{N}(-)$ form is more stable in the gas phase (see Computational Details and Table S1 in the Supporting Information). The most stable N(-) conformer at the MP2/aug-cc-pvtz level, labeled N(-)-1 (see Figure 2a), is planar and has $E$ conformation along the $\mathrm{C}_{16}-\mathrm{C}_{17}$ bond and $s$-trans and $s$-cis conformation along the $\mathrm{C}_{11}-\mathrm{C}_{15}$ and $\mathrm{C}_{17}-\mathrm{C}_{18}$ bonds, respectively, and it is approximately $2 \mathrm{kcal} \mathrm{mol}^{-1}$ more stable than the other N(-) isomers. This arrangement was also found in an NMR study of a fragment of the Kaede protein 
containing the red chromophore. ${ }^{21}$ In turn, the most stable $\mathrm{O}(-)$ conformer, $\mathrm{O}(-)-1$ (Figure $2 \mathrm{~b}$ ), has $E$, s-trans, s-trans conformation and is $3.6 \mathrm{kcal} \mathrm{mol}^{-1}$ higher in energy than $\mathrm{N}(-)-1$. These values are internal energies because calculation of the entropic contribution is not practical at this level of theory; however, our assignment of $\mathrm{N}(-)-1$ as the predominant gas-phase is confirmed by the calculated vertical detachment energies (VDEs) and the photoelectron spectroscopy data (see next section).

The relative stabilities in water have been estimated at the PCM/MP2/aug-cc-pvtz level. ${ }^{39}$ This approach does not consider specific $\mathrm{H}$ bonds but gives a first approximation of the solvation effect. $\mathrm{O}(-)-1$ is stabilized compared with $\mathrm{N}(-)-1$, and the two isomers have virtually the same energy, the difference being less than $0.01 \mathrm{kcal} \mathrm{mol}^{-1}$ (see SI). This suggests that in water there may be an equilibrium between the two forms. Overall, the deprotonation state of the rKaede chromophore is very sensitive to the environment, which is consistent with the $\mathrm{pH}$ dependence of the absorption spectrum of the red protein. ${ }^{19}$ The stabilization of $\mathrm{O}(-)-1$ in water is due to its larger dipole moment, 16.5 Debye compared to 9.7 Debye for N(-)-1 in the gas phase, and the deprotonation of the phenol ring found in the protein is probably a result of the neighboring residues, which favor the electronic density distribution of the $\mathrm{O}(-)$ form. 
Table 1 Vertical $\pi, \pi^{*}$ excitation energies $E_{\mathrm{ex}}$, and corresponding wavelengths $\lambda$, for the first five singlet excited states, $\mathrm{S}_{1}-\mathrm{S}_{5},{ }^{\mathrm{a}}$ of the $\mathrm{N}$-deprotonated rKaede chromophore (N(-)-1) at the MSCASPT2, TD-CAM-B3LYP and CC2 levels of theory. Oscillator strengths $f$ are in parentheses. The CASSCF/CASPT2 orbitals are presented in Fig. 3. $\mathrm{S}_{1}$ vertical excitations of the Odeprotonated species (O(-)-1) and MS-CASPT2 data for $p$-HBDI- included for comparison.

\begin{tabular}{|c|c|c|c|c|c|c|c|}
\hline & \multicolumn{3}{|c|}{$\begin{array}{c}\text { MS-CASPT2 }(14,14) / \\
\text { ANO-L }\end{array}$} & \multicolumn{2}{|c|}{$\begin{array}{l}\text { TD-CAM-B3LYP/ } \\
6-311++\mathrm{G}(3 \mathrm{df}, 3 \mathrm{pd})\end{array}$} & \multicolumn{2}{|c|}{$\mathrm{CC} 2 / \mathrm{cc}-\mathrm{pvtz}^{\mathrm{d}}$} \\
\hline & $E_{\mathrm{ex}} / \mathrm{eV}(f)$ & $\lambda / \mathrm{nm}$ & Character $^{c}$ & $E_{\mathrm{ex}} / \mathrm{eV}(f)$ & $\lambda / \mathrm{nm}$ & $E_{\mathrm{ex}} / \mathrm{eV}(f)$ & $\lambda / \mathrm{nm}$ \\
\hline $\mathrm{S}_{1}$ & $\begin{array}{l}2.49(1.138) \\
\text { O(-): } 2.24(1.03) \\
\text { HBDI: } 2.77(1.157)\end{array}$ & 499 & $\mathrm{H} \rightarrow \mathrm{L}(0.62)$ & $\begin{array}{l}2.66(1.266) \\
\mathrm{O}(-):^{\mathrm{e}} \quad 2.48 \\
(1.28)\end{array}$ & 466 & $\begin{array}{l}2.49(1.048) \\
\mathrm{O}(-):^{\mathrm{e}} \quad 2.04 \\
(1.14)\end{array}$ & 497 \\
\hline $\mathrm{S}_{2}$ & $\begin{array}{l}3.66(0.029) \\
\text { HBDI: } 3.99(0.038)\end{array}$ & 338 & $\begin{array}{l}\mathrm{H}-2 \rightarrow \mathrm{L}(0.26) \\
\mathrm{H}, \mathrm{H} \rightarrow \mathrm{L}, \mathrm{L}(0.25)\end{array}$ & $3.86(0.277)$ & 321 & $3.79(0.347)$ & 327 \\
\hline $\mathrm{S}_{3}$ & $\begin{array}{l}4.07(0.063) \\
\text { HBDI: } 4.10(0.073)\end{array}$ & 304 & $\begin{array}{l}\mathrm{H}-2 \rightarrow \mathrm{L}(0.24) \\
\mathrm{H} \rightarrow \mathrm{L}+1(0.24)\end{array}$ & $4.03(0.009)$ & 307 & $4.02(0.016)$ & 309 \\
\hline $\mathrm{S}_{4}$ & $\begin{array}{l}4.25(0.215) \\
\text { HBDI: } 4.78(0.013)\end{array}$ & 291 & $\begin{array}{l}\mathrm{H} \rightarrow \mathrm{L}+1(0.24) \\
\mathrm{H}-1 \rightarrow \mathrm{L}(0.23)\end{array}$ & $4.21(0.100)$ & 295 & $4.13(0.158)$ & 300 \\
\hline $\mathrm{S}_{5}$ & $\begin{array}{l}4.28(0.149)^{\mathrm{f}} \\
\text { HBDI: } 4.89(0.020)\end{array}$ & 290 & $\begin{array}{l}\mathrm{H} \rightarrow \mathrm{L}+2(0.31) \\
\mathrm{H}-3 \rightarrow \mathrm{L}(0.18)\end{array}$ & $4.44(0.077)$ & 279 & $4.21(0.060)$ & 294 \\
\hline
\end{tabular}

${ }^{a} \mathrm{n}, \pi^{*}$ states not included in the numbering. ${ }^{b}$ Excitation energies obtained at the SA-8-MSCASPT2(14,14)/ANO-L level. SA-8-MS-CASPT2(16,14)/ANO-S data for $p$-HBDI ${ }^{-}$included for comparison. "State character based on the PM-CASCI expansion from the MS-CASPT2 wave function. Squared coefficients given in brackets. ${ }^{\mathrm{d}}\left(\mathrm{n}, \pi^{*}\right)$ states: 3.78 and $3.94 \mathrm{eV}$. ${ }^{\mathrm{e}} \mathrm{S}_{1}$ vertical excitation of the O-deprotonated form $\left(\mathrm{O}(-)-1\right.$ in Figure 2). ${ }^{\mathrm{f}}$ Obtained at the SA-11-MSCASPT2(14,14)/ANO-L level.

Electronic structure of the rKaede chromophore. The vertical $\pi, \pi^{*}$ excitation energies of $\mathrm{N}(-)-1$, computed at the MS-CASPT2, TD-CAM-B3LYP and CC2 levels are presented in Table 1, and the corresponding orbitals in Figure 3. All methods agree in a bright lowest vertical 
excitation (oscillator strength 1.05-1.27) corresponding to the HOMO $\rightarrow$ LUMO transition. The excitation energy of $\mathrm{S}_{1}$ at the MS-CASPT2 and CC2 levels is $2.49 \mathrm{eV}$, while the TD-CAMB3LYP value is somewhat higher, $2.66 \mathrm{eV}$. For comparison, the $\mathrm{S}_{1}$ energy of the O-deprotonated form is $0.2-0.4 \mathrm{eV}$ lower (2.24 eV at the MS-CASPT2 level). At the MS-CASPT2 level, $\mathrm{S}_{2}$ of the $\mathrm{N}(-)-1$ form has predominantly HOMO-2 $\rightarrow$ LUMO character and appears at $3.66 \mathrm{eV}$. The $\mathrm{S}_{2}$ energies are higher with TD-CAMB3LYP and CC2 (3.86 and $3.79 \mathrm{eV})$ because of the partial double-excitation character that cannot be reproduced by TD-DFT or CC2. Because of this, $\mathrm{S}_{2}$ is only weakly absorbing at the MS-CASPT2 level (oscillator strength 0.029), while the oscillator strength at the TD-CAMB3LYP and CC2 levels is larger. There are three additional states between 3.9 and $4.5 \mathrm{eV}$, approximately, with the following energies at the MS-CASPT2 level: 4.07, 4.25 and $4.28 \mathrm{eV}$. Compared to the $p$-HBDI ${ }^{-}$anion, the MS-CASPT2 $\mathrm{S}_{1}-\mathrm{S}_{5}$ excitations of the rKaede chromophore are shifted to lower energies by $0.2-0.6 \mathrm{eV}$. For $\mathrm{S}_{1}$, the red shifts are approximately $0.3 \mathrm{eV}$ and $0.5 \mathrm{eV}$ for the $\mathrm{N}(-1)-1$ and $\mathrm{O}(-)-1$ isomers, respectively. This is consistent with the usual assumption that extended conjugation causes a red shift in the absorption. The lowest $\mathrm{n}, \pi^{*}$ states appear at 3.78 and $3.94 \mathrm{eV}$ at the $\mathrm{CC} 2$ level and are not considered further because they have oscillator strengths $<0.001$ and are only weakly coupled to the electron detachment continuum due to their Feshbach resonance character. 


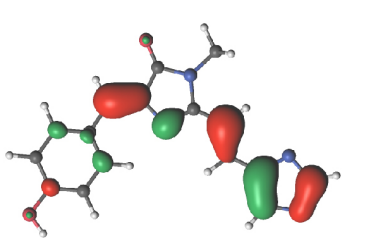

HOMO

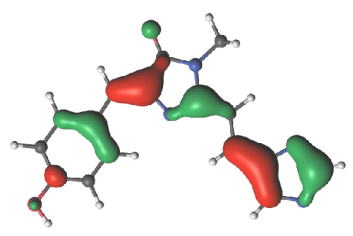

HOMO-1

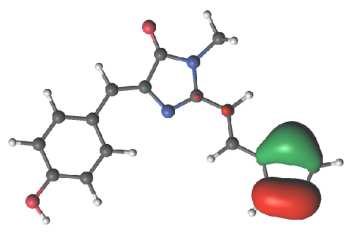

HOMO-2

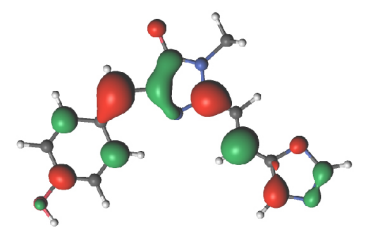

LUMO

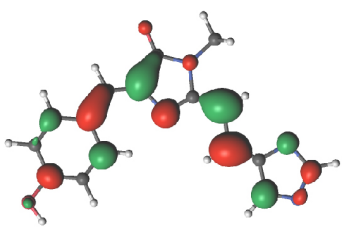

LUMO+1

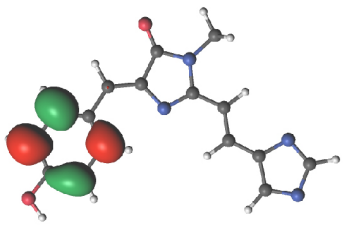

$\mathrm{LUMO}+2$

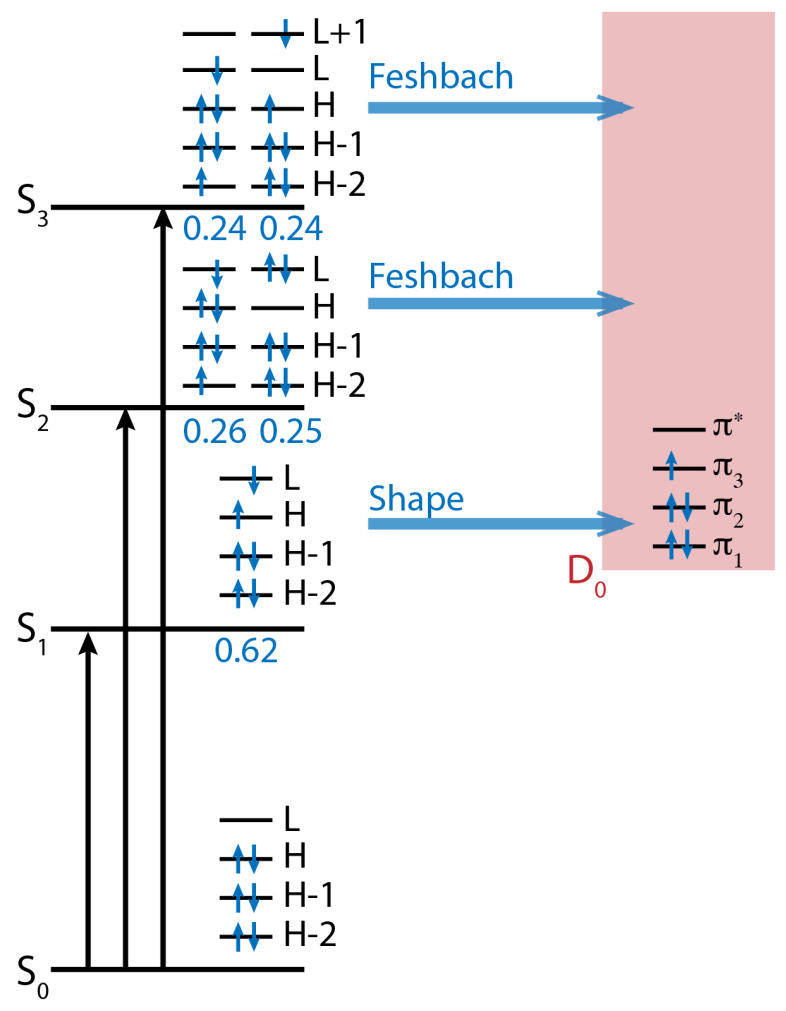

Fig. 3. Main CASSCF/MS-CASPT2 molecular orbitals involved in the transitions to the first three excited singlet electronic states of the rKaede chromophore and a schematic energy level diagram showing the resonance character (horizontal blue arrows) of these electronic states with respect to the $\mathrm{D}_{0}$ electronic continuum.

The MS-CASPT2 vertical $S_{1}$ energies of the deprotonated forms in water (see SI for details) have been calculated to be 2.52 and $2.76 \mathrm{eV}$ for $\mathrm{O}(-)-1$ and $\mathrm{N}(-)-1$. These values are in good agreement with the experimental band maximum of $2.55 \mathrm{eV}$, even though the calculations do not include vibronic effects which often shift the calculated absorption band to the red. ${ }^{40}$

The excited states were optimized at the CC2/cc-pvtz level of theory, ${ }^{41-42}$ and the energies were recalculated with MS-CASPT2. Our discussion is based on the MS-CASPT2 values, but there is overall good agreement between the relative energies of the two methods for all minima (see 
Table SI2 for a comparison of the two methods). All optimized structures were planar. The calculated band origin (0-0 transition) of $\mathrm{N}(-)-1$ in the gas phase is $2.42 \mathrm{eV}(513 \mathrm{~nm})$ at the MSCASPT2 level, which corresponds to a relaxation energy of approximately $0.1 \mathrm{eV}$. The most significant structural changes at the $S_{1}$ minimum are stretches of the $C_{8}-C_{9}, N_{10}-C_{11}$ and $C_{15}-C_{17}$ bonds by $0.03-0.05 \AA$ (see bond lengths in Figure 2a). This is consistent with the nodal structure of the orbitals involved in the excitation ( $\mathrm{H}$ and $\mathrm{L}$ in Figure 3), which are delocalized along the conjugated system. The $S_{2}$ state has a relaxation energy of $0.30 \mathrm{eV}$, and the relative MS-CASPT2 energy of the $S_{2}$ minimum $3.36 \mathrm{eV}$. The main changes in the bond lengths involve the imidazole ring, where the excitation is localized (see the H-2 orbital in Figure 3). At this structure, the energy of $S_{1}$ is $3.03 \mathrm{eV}$. The $S_{2} / S_{1}$ energy gap is reduced from $1.17 \mathrm{eV}$ at the Franck-Condon structure to $0.33 \mathrm{eV}$ at the $\mathrm{S}_{2}$ minimum, which suggests that there may be a nearlying conical intersection facilitating $S_{2} \rightarrow S_{1}$ internal conversion. Finally, optimization of $S_{3}$ at the CC2 level of theory leads to a state inversion and a minimum on $S_{2}$ with a relative MSCASPT2 energy of $3.66 \mathrm{eV}$. At this structure, the $\mathrm{S}_{3}$ energy is $3.75 \mathrm{eV}$. This suggests that excitation of $S_{3}$ will result in rapid internal conversion to $S_{2}$, and we postulate that this will be followed by further decay to $S_{1}$, like what is predicted to happen after $S_{2}$ excitation.

The photoelectron spectra of the deprotonated anionic model rKaede chromophore were recorded at 355,350 and $315 \mathrm{~nm}$ as a function of electron kinetic energy (eKE) and plotted as a function of electron binding energy, eBE $=h \nu$-eKE (Figure 4, solid black lines). The corresponding photoelectron spectra of $\mathrm{pHBDI}^{-}$are also presented for comparison (shaded grey) and are consistent with previous experimental photoelectron spectra measured by several groups, including our own group. ${ }^{18,29-32,43}$ It is clear that the rising edges of the photoelectron spectra for 
the rKaede and $p \mathrm{HBDI}^{-}$anions are independent of the laser wavelengths employed, a signature of direct electron detachment.

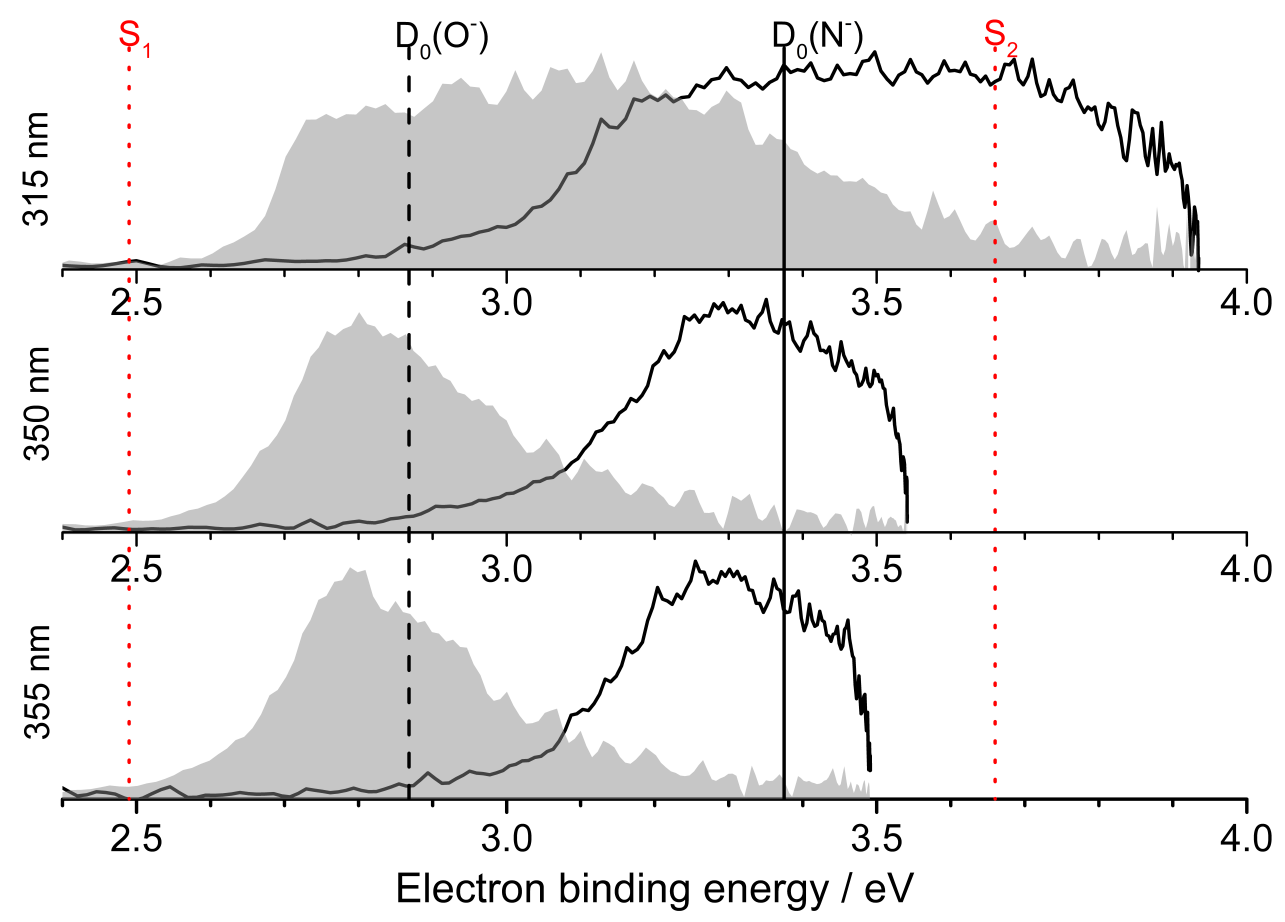

Fig. 4. Photoelectron spectra of the rKaede chromophore recorded at $355 \mathrm{~nm}(3.49 \mathrm{eV}), 350 \mathrm{~nm}$ $(3.54 \mathrm{eV})$ and $315 \mathrm{~nm}(3.94 \mathrm{eV})$ (solid black lines) compared with photoelectron spectra of $p \mathrm{HBDI}^{-}$(shaded grey). All spectra have been normalised to their maximum intensities. Black vertical lines mark the calculated VDEs of the $\mathrm{N}(-)-1$ (solid) and $\mathrm{O}(-)-1$ (dashed) forms of the rKaede chromophore, and dotted red vertical lines mark the vertical excitation energies of the first 2 excited singlet states of the deprotonated Kaede chromophore.

The eBE corresponding to the maximum intensities of the $355 \mathrm{~nm}$ spectra for the deprotonated rKaede chromophore and $\mathrm{pHBDI}^{-}$were estimated as the maxima of Gaussian functions fitted to the rising edges of the experimental spectra. The eBE estimated in this way for $p \mathrm{HBDI}^{-}$is $2.8 \pm$ 
$0.1 \mathrm{eV}$, which is close to the adiabatic detachment energy of $2.73 \pm 0.1 \mathrm{eV}$ determined from high resolution photoelectron spectra of vibrationally cold $p \mathrm{HBDI}^{-}{ }^{27}$ The eBE for the rKaede anion is estimated to be $3.3 \pm 0.1 \mathrm{eV}$, which is in good agreement with the value of $3.38 \mathrm{eV}$ calculated both with EPT/6-311++G(3dp,3df) and MS-CASPT2/ANO-L (see Computational Details in the SI). The VDE calculated for $\mathrm{O}(-)-1$ at the EPT level is $2.87 \mathrm{eV}$, which is sufficiently lower than the values estimated from experiment and calculated for $\mathrm{N}(-)-1$, to support our suggestion that the rKaede chromophore is generated in its $\mathrm{N}$-deprotonated form during electrospray ionization from methanol or methanol-water solutions. The $0.4 \mathrm{eV}$ blue shift of the VDE for the rKaede chromophore compared to $\mathrm{pHBDI}^{-}$can be rationalized in terms of the increased conjugation having a greater stabilizing effect on the anion than the neutral radical.

The slopes of the rising edges of the rKaede chromophore spectra are much shallower than those of $p \mathrm{HBDI}^{-}$, hinting at a larger difference between the VDE and adiabatic detachment energy (ADE) for the rKaede chromophore than for $p \mathrm{HBDI}^{-}$. This is indeed the case; the VDE and ADE for the rKaede chromophore at the MS-CASPT2 level are 3.38 and $3.15 \mathrm{eV}$, where the minimum of the ionized species was optimized at the B2PLYPD/cc-pvtz level of theory. ${ }^{44}$ The calculated relaxation energy upon ionization, $0.23 \mathrm{eV}$, is in good agreement with experiment (Fig. 4) and contrasts with $p \mathrm{HBDI}^{-}$for which calculations have determined that $\mathrm{ADE} \approx$ VDE. ${ }^{24,26,31-32,37}$ At the optimized $\mathrm{D}_{0}$ minimum, the main structural changes with respect to $\mathrm{S}_{0}$ are found in the imidazole ring (see bond lengths in Figure 2), which is consistent with the ring having a formal negative charge in the $\mathrm{N}(-)-1$ anion.

As the photon energy increases, the broad features in the photoelectron spectra change shape on the high eBE side, characteristic of indirect photodetachment processes following resonant excitation of a higher lying electronically excited state (autodetachment). This broadening has 
been observed before in $\mathrm{pHBDI}^{-}$and it was rationalized in terms of resonant excitation of a higher lying excited ${ }^{1} \pi \pi^{*}$ state, which has excited shape resonance character with respect to the lowest electronic continuum, and some contribution from a $1^{1} n \pi^{*}$ state, which is a Feshbach resonance. Similar effects have been observed in photoelectron spectra of deprotonated photoactive yellow protein (PYP) chromophore anions following resonant excitation of the higher lying $2^{1} \pi \pi^{*}$ state, which also has excited shape resonance character with respect to the lowest electronic continuum..$^{30,43}$

The photoelectron spectra of the rKaede chromophore all have significant intensities at low eKE (high eBE), unlike the photoelectron spectra of $p \mathrm{HBDI}^{-}$. However, the low eKE electrons do not have the characteristic exponential shape that is a signature of thermionic emission from the ground electronic state, nor do they have an intensity step that might indicate opening of a higher lying electron continuum. In fact, the VDE of $\mathrm{D}_{1}$ is calculated to be $4.70 \mathrm{eV}$ at the MSCASPT2 level for the rKaede chromophore, which is significantly higher than the highest photon energy used in our experiments $(3.94 \mathrm{eV})$, suggesting that direct detachment to the $\mathrm{D}_{1}$ continuum is unlikely. 


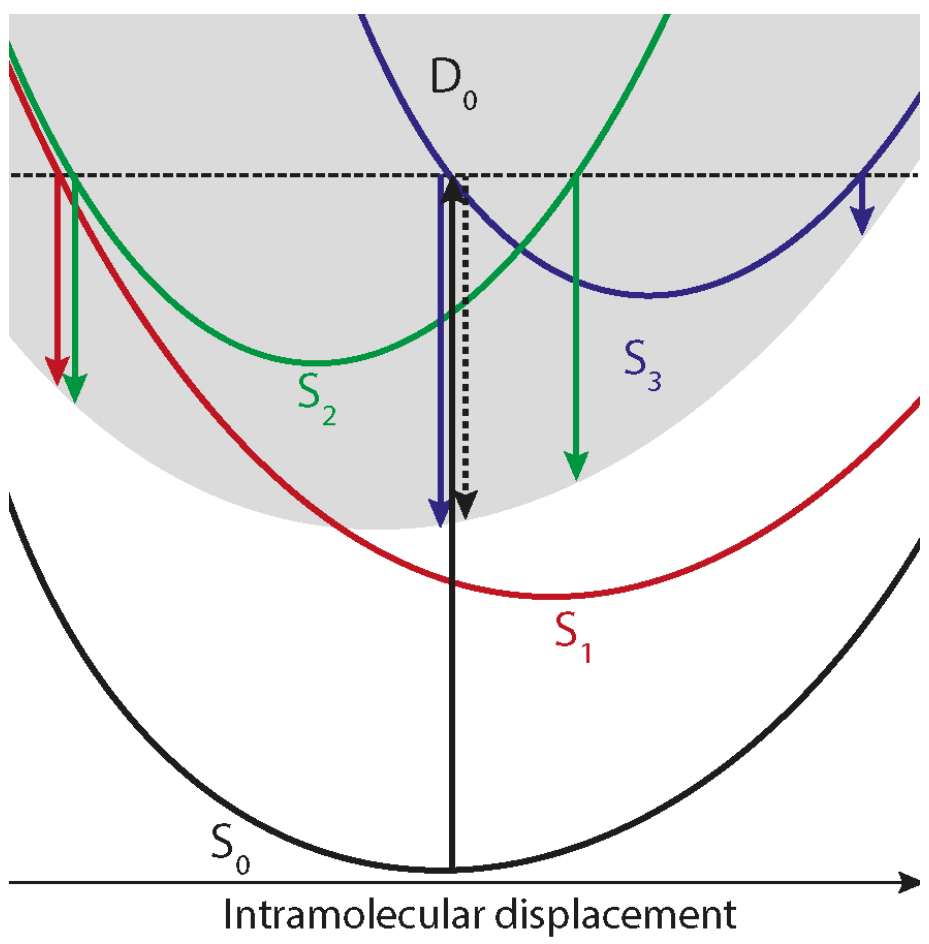

Fig. 5. Schematic potential energy level diagram illustrating competing electron detachment processes following photoexcitation of the $S_{3}$ state of the rKaede protein chromophore. The horizontal dashed line represents the final state energy and the solid grey shading represents the $D_{0}$ continuum. The solid black vertical arrow represents photoexcitation of the $S_{3}$ state. The dotted black vertical arrow represents direct detachment. Autodetachment to the $\mathrm{D}_{0}$ continuum is possible from electronically excited $S_{3}, S_{2}$ and $S_{1}$ states (vertical blue, green and red arrows, respectively) from any point along the intramolecular displacement coordinate lying in the $\mathrm{D}_{0}$ continuum.

In Fig. 5, the possible electronic relaxation and electron emission processes following photoexcitation of the $S_{3}$ state of the rKaede protein chromophore are shown on a schematic 
potential energy diagram. The $S_{3}$ and $S_{2}$ states have a Feshbach resonance character with respect to the $D_{0}$ continuum, whereas the $S_{1}$ state is predominantly a shape resonance. Thus, $S_{3}$ and $S_{2}$ are only weakly coupled to the electronic continuum. Moreover, the $S_{3}$ and $S_{2}$ optimizations suggest that excitation of $S_{3}$ will be followed by rapid, sequential internal conversion to $S_{2}$ and $S_{1}$. Therefore, internal conversion to $S_{1}$ is likely to be more efficient than autodetachment from either $S_{3}$ and $S_{2}$. This is similar to the efficient and rapid internal conversion that has been observed to occur through a series of conical intersections between excited states, that are unbound with respect to electron detachment, in para-benzoquinone. ${ }^{45}$ Because $S_{1}$ is a shape resonance with respect to the $D_{0}$ continuum, the coupling between $S_{1}$ and $D_{0}$ is strong and autodetachment from $S_{1}$ to $D_{0}$ will be fast. The absence of an exponential tail of low eKE electrons, characteristic of thermionic emission from the hot electronic ground state, suggests that autodetachment from high vibrational levels of $S_{1}$ is faster than internal conversion to the electronic ground state. This in turn suggests that autodetachment from high lying vibrational states in $S_{1}$ is responsible for the continuum of low eKE electrons observed in the $315 \mathrm{~nm}$ photoelectron spectrum of rKaede. It is worth noting that $S_{4}$ and $S_{5}$ may also contribute to the continuum of low eKE in the $315 \mathrm{~nm}$ spectrum of rKaede by similar rapid internal conversion through a series of conical intersections to $S_{1}$.

The continuum of low eKE (high eBE) electrons seems likely to be a signature of autodetachment from high vibrational levels of a low lying excited electronic state and indeed such a continuum is also observed in the static photoelectron spectrum of para-benzoquinone, in addition to the exponential tail arising from thermionic emission from a hot ground state. ${ }^{45} \mathrm{~A}$ continuum of low eKE electrons is not observed in the $315 \mathrm{~nm}$ photoelectron spectrum of $p \mathrm{HBDI}^{-}$, although a broadening of the photoelectron spectrum towards high eBE is observed. 
This is readily understood in terms of the characters of the excited states. In $p \mathrm{HBDI}^{-}$, the $\mathrm{S}_{1}, \mathrm{~S}_{2}$ and $\mathrm{S}_{3}$ states are shape, Feshbach and excited-shape resonances, respectively, with respect to the $\mathrm{D}_{0}$ continuum. ${ }^{37}$ Thus, in $p \mathrm{HBDI}^{-}$the $\mathrm{S}_{3}$ state that is accessible at $315 \mathrm{~nm}$ is so strongly coupled to the $\mathrm{D}_{0}$ electronic continuum that it will undergo rapid autodetachment, resulting in a broadening of the photoelectron spectrum to lower eKEs (higher eBE) but not to a continuum at very low eKE.

In summary, the comparison between UV photoelectron spectra of the rKaede protein chromophore and the GFP chromophore suggests that there is an efficient electronic relaxation pathway from higher lying electronically excited states to the $S_{1}$ state in the rKaede chromophore that is not in operation in the GFP chromophore. Specifically, relaxation of $S_{2}$ facilitates $S_{2} \rightarrow S_{1}$ internal conversion after excitation to $S_{2}$ and $S_{3}$. This is a result of increasing the conjugation, since the state that facilitates internal conversion to $S_{1}\left(S_{2}\right.$ at the Franck-Condon geometry) has H-2->L configuration, i.e. it involves an occupied orbital on the imidazole ring which is not present in $p \mathrm{HBDI}^{-}$. Therefore, the extension of the $p \mathrm{HBDI}^{-}$chromophore with the imidazole group causes the appearance of an additional state that is responsible for the suppression of autodetachment from $\mathrm{S}_{2}$, suggesting that electron transfer from rKaede to the solvent will be less efficient than in GFP. We believe this may be a general effect in large chromophores. This work highlights the importance of detailed spectroscopic and dynamical studies of the rKaede protein and of other green-to-red photoconvertible proteins so we may improve our understanding of how to improve the properties of fluorescent protein optical markers that are not only used in the biological and biomedical sciences as genetically coded fluorescent markers but are also important tools for super resolution imaging. ${ }^{46-47}$ 
Supporting Information: Computational details, experimental methods and Cartesian coordinates for $\mathrm{N}(-)-1$ structures.

Acknowledgments: L.B. acknowledges financial support from the Spanish Ministerio de Economía y Competitividad (CTQ2015-69363-P), the Generalitat de Catalunya (2014SGR1202), and computational time from the Consorci de Serveis Universitaris de Catalunya. J.T., M.A.P. and H.H.F. acknowledge support from the EPSRC (EP/L005646/1) and the EPSRC UK National Service for Computational Chemistry Software (NSCCS) at Imperial College London as well as computational support from Dr Jorg Saßmannshausen at UCL. 


\section{References.}

1. Meech, S. R. Excited State Reactions in Fluorescent Proteins. Chem. Soc. Rev. 2009, 38, 2922-2934.

2. Chalfie, M.; Tu, Y.; Euskirchen, G.; Ward, W. W.; Prasher, D. C. Green Fluorescent Protein as a Marker for Gene Expression. Science 1994, 263, 802-805.

3. Mooney, C. R. S.; Horke, D. A.; Chatterley, A. S.; Simperler, A.; Fielding, H. H.; Verlet, J. R. R. Taking the Green Fluorescence out of the Protein: Dynamics of the Isolated GFP Chromophore Anion. Chem. Sci. 2013, 4, 921-927.

4. Tsien, R. Y. The Green Fluorescent Protein. Annu. Rev. Biochem 1998, 67, 509-544.

5. Zimmer, M. Green Fluorescent Protein (GFP): Applications, Structure, and Related Photophysical Behavior. Chem. Rev. 2002, 102, 759-781.

6. Acharya, A.; Bogdanov, A. M.; Grigorenko, B. L.; Bravaya, K. B.; Nemukhin, A. V.; Lukyanov, K. A.; Krylov, A. I. Photoinduced Chemistry in Fluorescent Proteins: Curse or Blessing? Chem. Rev. 2016.

7. $\quad$ Cody, C. W.; Prasher, D. C.; Westler, W. M.; Prendergast, F. G.; Ward, W. W. Chemical Structure of the Hexapeptide Chromophore of the Aequorea Green Fluorescent Protein. Biochemistry 1993, 32, 1212-1218.

8. Cubitt, A. B.; Heim, R.; Adams, S. R.; Boyd, A. E.; Gross, L. A.; Tsien, R. Y. Understanding, Improving and Using Green Fluorescent Proteins. Trends Biochem. Sci. 1995, 20, 448-455.

9. Heim, R.; Prasher, D. C.; Tsien, R. Y. Wavelength Mutations and Posttranslational Autoxidation of Green Fluorescent Protein. Proc. Natl. Acad. Sci. USA 1994, 91, 12501-12504. 10. Ormo, M.; Cubitt, A. B.; Kallio, K.; Gross, L. A.; Tsien, R. Y.; Remington, S. J. Crystal Structure of the Aequorea Victoria Green Fluorescent Protein. Science 1996, 273, 1392-1395. 11. Chattoraj, M.; King, B. A.; Bublitz, G. U.; Boxer, S. G. Ultra-Fast Excited State Dynamics in Green Fluorescent Protein: Multiple States and Proton Transfer. Proc. Natl. Acad. Sci. USA 1996, 93, 8362-8367.

12. Kojima, S.; Ohkawa, H.; Hirano, T.; Maki, S.; Niwa, H.; Ohashi, M.; Inouye, S.; Tsuji, F. I. Fluorescent Properties of Model Chromophores of Tyrosine-66 Substituted Mutants of Aequorea Green Fluorescent Protein (GFP). Tetrahedron Lett. 1998, 39, 5239-5242.

13. Morise, H.; Shimomur.O; Johnson, F. H.; Winant, J. Intermolecular Energy Transfer in Bioluminescent System of Aequorea. Biochemistry 1974, 13, 2656-2662.

14. Ward, W. W.; Cody, C. W.; Hart, R. C.; Cormier, M. J. Spectrophotometric Identity of the Energy Transfer Chromophores in Renilla and Aequorea Green Fluorescent Proteins. Photochem. Photobiol. 1980, 31, 611-615.

15. Lossau, H.; Kummer, A.; Heinecke, R.; Pöllinger-Dammer, F.; Kompa, C.; Bieser, G.; Jonsson, T.; Silva, C. M.; Yang, M. M.; Youvan, D. C.; Michel-Beyerle, M. E. Time-Resolved Spectroscopy of Wild-Type and Mutant Green Fluorescent Proteins Reveals Excited State Deprotonation Consistent with Fluorophore-Protein Interactions. Chem. Phys. 1996, 213, 1-16. 16. Forbes, M. W.; Jockusch, R. A. Deactivation Pathways of an Isolated Green Fluorescent Protein Model Chromophore Studied by Electronic Action Spectroscopy. J. Amer. Chem. Soc. 2009, 131, 17038-17039. 
17. Niwa, H.; Inouye, S.; Hirano, T.; Matsuno, T.; Kojima, S.; Kubota, M.; Ohashi, M.; Tsuji, F. I. Chemical Nature of the Light Emitter of the Aequorea Green Fluorescent Protein. Proc. Natl. Acad. Sci. USA 1996, 93, 13617-13622.

18. Mooney, C. R. S.; Sanz, M. E.; McKay, A. R.; Fitzmaurice, R. J.; Aliev, A. E.; Caddick, S.; Fielding, H. H. Photodetachment Spectra of Deprotonated Fluorescent Protein Chromophore Anions. J. Phys. Chem. A 2012, 116, 7943-7949.

19. Ando, R.; Hama, H.; Yamamoto-Hino, M.; Mizuno, H.; Miyawaki, A. An Optical Marker Based on the UV-Induced Green-to-Red Photoconversion of a Fluorescent Protein. Proc. Natl. Acad. Sci. USA 2002, 99, 12651-12656.

20. Elowitz, M. B.; Surette, M. G.; Wolf, P. E.; Stock, J.; Leibler, S. Photoactivation Turns Green Fluorescent Protein Red. Curr. Biol. 1997, 7, 809-812.

21. Mizuno, H.; Mal, T. K.; Tong, K. I.; Ando, R.; Furuta, T.; Ikura, M.; Miyawakil, A. Photo-Induced Peptide Cleavage in the Green-to-Red Conversion of a Fluorescent Protein. Mol. Cell 2003, 12, 1051-1058.

22. Yampolsky, I. V.; Kislukhin, A. A.; Amatov, T. T.; Shcherbo, D.; Potapov, V. K.; Lukyanov, S.; Lukyanov, K. A. Synthesis and Properties of the Red Chromophore of the Greento-Red Photoconvertible Fluorescent Protein Kaede and Its Analogs. Bioorg. Chem. 2008, 36, 96-104.

23. Hayashi, I.; Mizuno, H.; Tong, K. I.; Furuta, T.; Tanaka, F.; Yoshimura, M.; Miyawaki, A.; Ikura, M. Crystallographic Evidence for Water-Assisted Photo-Induced Peptide Cleavage in the Stony Coral Fluorescent Protein Kaede. J. Mol. Biol. 2007, 372, 918-926.

24. Bochenkova, A. V.; Klaerke, B.; Rahbek, D. B.; Rajput, J.; Toker, Y.; Andersen, L. H. UV Excited-State Photoresponse of Biochromophore Negative Ions. Angew. Chem., Int. Ed. 2014, 53, 9797-9801.

25. Andersen, L. H.; Bluhme, H.; Boye, S.; Jorgensen, T. J. D.; Krogh, H.; Nielsen, I. B.; Nielsen, S. B.; Svendsen, A. Experimental Studies of the Photophysics of Gas-Phase Fluorescent Protein Chromophores. Phys. Chem. Chem. Phys. 2004, 6, 2617-2627.

26. Bochenkova, A. V.; Andersen, L. H. Ultrafast Dual Photoresponse of Isolated Biological Chromophores: Link to the Photoinduced Mode-Specific Non-Adiabatic Dynamics in Proteins. Faraday Discuss. 2013, 163, 297-319.

27. Deng, S. H. M.; Kong, X.-Y.; Zhang, G.; Yang, Y.; Zheng, W .-J.; Sun, Z.-R.; Zhang, D.Q.; Wang, X.-B. Vibrationally Resolved Photoelectron Spectroscopy of the Model GFP Chromophore Anion Revealing the Photoexcited $\mathrm{S}_{1}$ State Being Both Vertically and Adiabatically Bound against the Photodetached $\mathrm{D}_{0}$ Continuum. J. Phys. Chem. Lett. 2014, 5 , 2155-2159.

28. Forbes, M. W.; Nagy, A. M.; Jockusch, R. A. Photofragmentation of and Electron Photodetachment from a GFP Model Chromophore in a Quadrupole Ion Trap. Int. J. Mass spectrom. 2011, 308, 155-166.

29. Horke, D. A.; Verlet, J. R. R. Photoelectron Spectroscopy of the Model GFP Chromophore Anion. Phys. Chem. Chem. Phys. 2012, 14, 8511-8515.

30. Mooney, C. R. S.; Parkes, M. A.; Iskra, A.; Fielding, H. H. Controlling Radical Formation in the Photoactive Yellow Protein Chromophore. Angew. Chem., Int. Ed. 2015, 54, 5646-5649.

31. Mooney, C. R. S.; Parkes, M. A.; Zhang, L.; Hailes, H. C.; Simperler, A.; Bearpark, M. J.; Fielding, H. H. Competition between Photodetachment and Autodetachment of the $2^{1} \mathrm{pp}^{*}$ State of the Green Fluorescent Protein Chromophore Anion. J. Chem. Phys. 2014, 140, 205103. 
32. Toker, Y.; Rahbek, D. B.; Klaerke, B.; Bochenkova, A. V.; Andersen, L. H. Direct and Indirect Electron Emission from the Green Fluorescent Protein Chromophore. Phys. Rev. Lett. 2012, 109, 128101.

33. West, C. W.; Bull, J. N.; Hudson, A. S.; Cobb, S. L.; Verlet, J. R. R. Excited State Dynamics of the Isolated Green Fluorescent Protein Chromophore Anion Following UV Excitation. J. Phys. Chem. B 2015, 119, 3982-3987.

34. West, C. W.; Hudson, A. S.; Cobb, S. L.; Verlet, J. R. R. Autodetachment Versus Internal Conversion from the $\mathrm{S}_{1}$ State of the Isolated GFP Chromophore Anion. J. Chem. Phys. 2013, 139, 071104.

35. McLaughlin, C.; Assmann, M.; Parkes, M. A.; Woodhouse, J. L.; Lewin, R.; Hailes, H. C.; Worth, G. A.; Fielding, H. H. Ortho and Para Chromophores of Green Fluorescent Protein: Controlling Electron Emission and Internal Conversion. Chem. Sci. 2017, DOI: 10.1039/c6sc03833f.

36. Bravaya, K. B.; Krylov, A. I. On the Photodetachment from the Green Fluorescent Protein Chrornophore. J. Phys. Chem. A 2013, 117, 11815-11822.

37. Bochenkova, A. V.; Mooney, C. R. S.; Parkes, M. A.; Woodhouse, J. L.; Zhang, L.; Lewin, R.; Ward, J. M.; Hailes, H. C.; Andersen, L. H.; Fielding, H. H. Mechanism of Resonant Electron Emission from the Deprotonated GFP Chromophore and Its Biomimetics. Chem. Sci. 2017, in press.

38. Walba, H.; Isensee, R. W. Acidity Constants of Some Arylimidazoles and Their Cations. J. Org. Chem. 1961, 26, 2789-2791.

39. Cossi, M.; Rega, N.; Scalmani, G.; Barone, V. Energies, Structures, and Electronic Properties of Molecules in Solution with the C-Pcm Solvation Model. J. Comput. Chem. 2003, 24, 669-681.

40. Avila Ferrer, F. J.; Cerezo, J.; Stendardo, E.; Improta, R.; Santoro, F. Insights for an Accurate Comparison of Computational Data to Experimental Absorption and Emission Spectra: Beyond the Vertical Transition Approximation. J. Chem. Theory Comput. 2013, 9, 2072-82. 41. Kats, D.; Schütz, M. A Multistate Local Coupled Cluster CC2 Response Method Based on the Laplace Transform. J. Chem. Phys. 2009, 131, 124117.

42. Ledermueller, K.; Schütz, M. Local CC2 Response Method Based on the Laplace Transform: Analytic Energy Gradients for Ground and Excited States. J. Chem. Phys. 2014, 140, 164113.

43. Parkes, M. A.; Phillips, C.; Porter, M. J.; Fielding, H. H. Controlling Electron Emission from the Photoactive Yellow Protein Chromophore by Substitution at the Coumaric Acid Group. Phys. Chem. Chem. Phys. 2016, 18, 10329-10336.

44. Schwabe, T.; Grimme, S. Double-Hybrid Density Functionals with Long-Range Dispersion Corrections: Higher Accuracy and Extended Applicability. Phys. Chem. Chem. Phys. 2007, 9, 3397-3406.

45. Horke, D. A.; Li, Q.; Blancafort, L.; Verlet, J. R. R. Ultrafast above-Threshold Dynamics of the Radical Anion of a Prototypical Quinone Electron-Acceptor. Nat. Chem. 2013, 5, 711-717. 46. Dempsey, G. T.; Vaughan, J. C.; Chen, K. H.; Bates, M.; Zhuang, X. Evaluation of Fluorophores for Optimal Performance in Localization-Based Super-Resolution Imaging. Nat. Methods 2011, 8, 1027-1036.

47. Heilemann, M.; van de Linde, S.; Mukherjee, A.; Sauer, M. Super-Resolution Imaging with Small Organic Fluorophores. Angew. Chem., Int. Ed. 2009, 48, 6903-6908. 


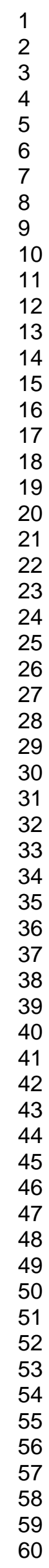

